\title{
Effect of Using Staples on Early Functional and Surgical Outcomes in Anterior Vertebral Body Tethering
}

Bant ile Gerdirme Yönteminde Pul Kullanmanın Erken Dönem İşlevsel ve Cerrahi Sonuçlara Etkileri

\section{Çağlar YILGÖR}

Acibadem Mehmet Ali Aydinlar University School of Medicine, Department of Orthopedics and Traumatology, Istanbul, Turkey

\section{öz}

Amaç: Bant ile gerdirme yöntemi, adölesan idiyopatik skolyozda füzyon cerrahisine umut verici bir alternatiftir. Ameliyattaki düzelmeyi takipte büyümeye bağlı ek düzelme izler. Çalışmanın amacı, bant ile gerdirmede vida yerleştirilirken pul kullanımının erken dönem cerrahi ve işlevsel sonuçlar ve implantla ilişkili komplikasyonlar üzerindeki etkisini incelemektir.

Gereç ve Yöntem: Çalışmaya . 3 aylık izlemi olan ardışık 27 hasta alındı. Hastalar pul kullanımına göre 2 gruba ayrıldı. Günlük yaşam aktivitelerine dönüş, cerrahi sonuçlar, yaşam kalite anket sonuçları ve komplikasyonlar kaydedildi. Pul kullanımının etkileri Mann-Whitney U testi kullanılarak karşılaştırıldı.

Sonuçlar: Hastanede kalış ve okula dönüş süreleri iki grupta benzerdi. Her iki grupta yaşam kalite anketlerinde işlevsel aktivite, ağrı, görünüm algısı ve ruh sağlığı alanlarında benzer iyileşmeler saptandı. Tüm hastalar rehabilitasyon hedeflerine ulaştı. Pul kullanılmayan gruptaki hastalar daha sıklıkla implantla ilişkili komplikasyon yaşadı.

Tartışma: Bant ile gerdirme yönteminde vidalar yerleştirilirken pul kullanılması implantla ilişkili komplikasyonları azaltabilir. Bu cerrahi yöntem pul kullanımından bağımsız olarak erken dönemde iyi işlevsel ve cerrahi sonuçlar ve yüksek hasta memnuniyeti sağlamıştır. Bu çalışmada elde edilen bulgular ışığında vidalar yerleştirilirken pul kullanılan ve kullanılmayan gruplarda biyomekanik yüklere karşı dirençte öne sürülen farklılık hastaların ameliyat sonrası rehabilitasyon süreçlerinin planlanmasında önemli olabilir.

Anahtar kelimeler: Adölesan idiyopatik skolyoz; Anterior vertebral tethering; Büyüme yönlendirmesi; İmplantla ilişkili komplikasyonlar; Ameliyat sonrası rehabilitasyon

\section{A B S T R ACT}

Purpose: Anterior vertebral body tethering (VBT) is a promising alternative to fusion surgery for adolescent idiopathic scoliosis (AIS). Initial surgical correction is tailed by additional correction attained during follow-up. This study aims to analyze the effect of using staples on early functional and surgical outcomes, and implantrelated complications of VBT surgery.

Material and Methods: Twenty-seven consecutive patients with.3-months follow-up were included. Patients were divided into two groups based on the use of staples to facilitate screw insertion. Return to daily-living activities, surgical outcomes, patient-reported outcomes and complications were recorded as outcome data. Mann-Whitney $U$ test was used to compare the effect of using staples. 
Results: The mean hospitalization period and days to return to school was not different between groups. Patientreported outcomes revealed similar increase in function, pain, self-image and mental-health with high satisfaction rates in both groups. All patients reached rehabilitation goals. Patients in non-staple group experienced more implant-related complications.

Conclusion: Using staples in VBT surgery may decrease implant-related complications. VBT surgery revealed good functional and surgical outcomes, and high satisfaction rate regardless of the use staples. The suggested difference in resistance to biomechanical loads in the staple and non-staple groups, might be important in planning postoperative rehabilitation.

Keywords: Adolescent idiopathic scoliosis; Anterior vertebral body tethering; Growth modulation; Implant-related complications; Postoperative rehabilitation

Scoliosis is a three-dimensional deformity of the spine. Adolescent Idiopathic Scoliosis (AIS) is the most common type, accounting for nearly $80 \%$ of all cases with scoliosis (Asher \& Burton, 2006). The growth of the deformed spine influences the growth of the remaining spine, chest wall, lungs and extremities (Akbarnia, 2007). Therefore, respecting the remaining spinal growth is essential when planning treatment. The natural history of skeletally immature idiopathic scoliosis with moderate curves is progression (Asher \& Burton, 2006). A study reported $75 \%$ of pubertal onset curves between $210-300$ and $100 \%$ of patients with $>30$ o curves required spinal fusion with observation alone (Charles, Daures, de Rosa et al., 2006). Currently, observation is recommended for curves $<200$, bracing for curves between $20-$ 400 , and surgery for curves exceeding 40 degrees (Gomez, Hresko, \& Glotzbecker, 2016).

Bracing in Adolescent Idiopathic Scoliosis Trial (BrAIST) study suggests that appropriately prepared and worn braces would be effective, however, not for every single patient and all curve types (Weinstein, Dolan, Wright et al., 2013). Furthermore, bracing may be uncomfortable and require serious commitment of the patient. Patients who fail bracing and whose curves reach $40^{\circ}$ are often offered surgical treatment.

Posterior spinal fusion, using segmental spinal instrumentation techniques, is the mainstay of surgical deformity correction. Although, spinal fusion stands effective, it limits motion, inhibits growth over the length of the construct, and it is not without complications (Green, Lawhorne, Widmann et al., 2011; Kepler, Meredith, Green et al., 2012).

Non-fusion surgical techniques are used in order to postpone or avoid fusion, to achieve deformity correction while allowing spinal, thoracic cage and thus, lung growth. Performed via a minimally invasive thoracoscopic approach, growth modulation with anterior vertebral body tethering (VBT) is a promising alternative to bracing and fusion surgery for pediatric scoliosis (Yilgor \& Alanay, 2017).

The purpose of VBT is to harness the patient's inherent spinal growth and redirect it to achieve correction of the curve rather than progression (Guille, D'Andrea, \& Betz, 2007). This is achieved by the placement of vertebral body screws on the convexity and then attaching a polyethylene tether, which is shortened and tightened applying compressive forces on convex side of the vertebral bodies. Decelerating the growth rate at the convexity, VBT allows more concave growth, gradually decreasing curve magnitude.

Biomechanical basis for tethering was demonstrated in a goat model (Braun, Akyuz, Ogilvie et al., 2005) presenting good efficacy and integrity. The authors concluded that the tether provided flexibility that decreased forces during spinal motion and protected the bone anchors from loosening. This was confirmed in a porcine model suggesting that this increased flexibility possibly contributed to greater mobility and as a consequence, lowers the risk of spontaneous fu- 
sion (Newton, Upasani, Farnsworth et al., 2008). However, a recent report suggests that the initial surgical correction is followed by a relaxation/ adaptation period during the first 6-12 weeks, consequently followed by progressive improvement (Cebeci, Ergene, Sogunmez et al., 2017). This initial adaptation period where the Cobb angle magnitude increases, may further tighten the tether and alter the forces on the screws applied by the tether. As such, this period may be prone to implant-related complications.

Although persistent atelectasis, worsening of the deformity and overcorrection have been reported after VBT surgery (Samdani, Ames, Kimball et al., 2014, 2015), to date, implant-related complications were not explored and reported. Tether breakage may also be a concern. Yet, since the tether is radiolucent, it necessitates close observation of the segmental angular changes to be identified.

During VBT surgery, screws can either be directly placed to the vertebral body or a 3- or 4-prong staple may be used to facilitate insertion and stabilization (Yilgor \& Alanay, 2017). Absence or presence of staples may alter the mechanics of the construct resulting in different biomechanical environment, and thus different mechanical complication rates.

This study aims to analyze the effect of using staples on early functional and surgical outcomes, and implant-related complications of VBT surgery.

\section{Materials and Methods Patient Inclusion Criteria}

After obtaining institutional review board approval (2016-11/11), clinical and radiographical data for all patients who signed informed consent form and underwent anterior vertebral body tethering at the Comprehensive Spine Center at AClbadem Maslak Hospital was retrospectively reviewed. Follow-up visits were carried on 6th week, and 3rd, 6th, 12th, 18th, 24th and 36th months postoperatively. Inclusion criteria for this specific study was to have main thoracic curve tethered and to have at least 3-months' of follow-up.

Surgeries were performed according to the previously reported technique (Samdani et al.,
2014; Yilgor et al., 2017). Hydroxyapatite coated screws were used in all cases. In the beginning of experience, screws were directly applied to the vertebral body. These patients formed the nonstaple group. Later, 4-prong staples were used at each level to facilitate screw insertion. Patients, in whom staples were used, formed the staple group.

\section{Radiographic Evaluation}

Radiographic measurements included the following variables: Upper instrumented vertebra (UIV) and lower instrumented vertebra (LIV); coronal main thoracic and lumbar curve Cobb angles; thoracic kyphosis and lumbar lordosis Cobb angles; Cobb angle between the UIV screw and UIV upper end-plate, and Cobb angles between each screw. Cobb angle measurements were recorded at the following time points: preoperative, immediately postoperative (first erect), at each follow-up.

\section{Rehabilitation Protocol}

Rehabilitation goals and exercises performed in postoperative first 12 weeks are described in table 1. Trunk bending and lifting were limited until wound healing. High velocity movements and prolonged sitting were limited until the patients were pain-free without medication.

\section{Outcome Data}

Outcome data was collected in four main categories as: Return to activities of daily living, surgical outcomes, patient-reported outcomes and complications.

Length of hospital stay, days to return to school and reaching rehabilitation protocol goals were recorded to evaluate the return to activities of $\mathrm{da}-$ ily living. Main thoracic and lumbar curve surgical correction percentages and relaxation that takes place in the first 6-12 weeks as well as change in height and forced vital lung capacity were recorded as surgical outcomes. Scoliosis Research Society spinal deformity questionnaire (SRS-22) completed preoperatively and at each follow-up was used as the health-related quality-of-life measure. SRS-22 was used to evaluate patientreported function, pain, self-image, mental health and satisfaction. Pulmonary and implant-related complications were recorded. 
Table 1: Description of the rehabilitation protocol

\begin{tabular}{|c|c|c|}
\hline & Goals & Exercises \\
\hline Until Discharge & $\begin{array}{c}\text { Independent in-bed mobility by day } 0 \\
\text { Sit-to-stand and walking sessions by day } 1 \\
\text { Climb one flight up \& down }\end{array}$ & $\begin{array}{l}\text { Walking progression on level surface } \\
\text { with no/minimal assistance } \\
\text { Respiratory exercises } \\
50 \text { step walking test }\end{array}$ \\
\hline First 2 weeks & $\begin{array}{l}\text { Increase pain-free walking tolerance to } 30 \\
\text { minutes } \\
\text { Increase pain-free sitting tolerance } \\
\text { Increase daily flights climbed } \\
\text { Return to school }\end{array}$ & $\begin{array}{l}\text { Repeated sit-to-stand } \\
\text { Supine / prone / seated / standing } \\
\text { transvers abdominal strengthening } \\
\text { Supine gluteal \& hip abductor } \\
\text { progression } \\
\text { Supported quarter wall slide } \\
\text { Respiratory exercises }\end{array}$ \\
\hline 2-6 weeks & $\begin{array}{l}\text { Full return to activities of daily living } \\
\text { Walk on level surface without restrictions }\end{array}$ & $\begin{array}{l}\text { Supine / prone / seated / standing } \\
\text { advanced transvers abdominal exercises } \\
\text { Advanced gluteal \& bridging exercises } \\
\text { Advance hip abductor strengthening }\end{array}$ \\
\hline 6-12 weeks & $\begin{array}{l}\text { Walk on all surfaces without restrictions } \\
\text { Climb flights without restrictions }\end{array}$ & $\begin{array}{l}\text { Jogging } \\
\text { Cycling } \\
\text { Swimming }\end{array}$ \\
\hline
\end{tabular}

\section{Statistical Analysis}

Descriptive statistics were used to define the demographic and clinical details. Mann-Whitney $U$ test was used to compare length of hospital stay, days to return to school, coronal and sagittal surgical correction rates, change in screw and screw-upper end-plate angles during the relaxation period, increase in postoperative height and SRS-22 scores. A p-value, 0.05 indicated significance, reported along with the U-value calculated by 2 -tailed testing. The $\mathrm{U}$-value represents the number of times observations in one sample precede observations in the other sample in ranking.

\section{Results \\ Patient Characteristics}

Twenty-seven consecutive patients operated between April 2014 and August 2017 were included. Thirteen patients were in the non-staple group with a mean age of 12.4 (11-14) and mean followup of 19.2 months (10-41). Twelve were female and one was male. Nine $(75 \%)$ of the female patients were pre-menarche.

Fourteen patients were in the staple group with a mean age of $12.3(10-14)$ and mean follow-up of
4.8 months (3-10). Thirteen were female and one was male. Nine $(69 \%)$ of the female patients were pre-menarche.

\section{Radiographic Results}

A mean of 7.4 levels were tethered in the nonstaple group. UIV was T5 or T6 in all cases. LIV was T11-T12 or L1. Similarly, a mean of 7.8 levels were tethered in the staple group. UIV was T7 in one case, and T5 or T6 in rest of the cases. LIV was T11-T12-L1-L2 or L3.

For main thoracic and lumbar curve Cobb measurements, preoperative curve magnitudes, surgical correction percentages and relaxation that takes place in the first 6-12 weeks were similar in two groups. Hypokyphosing effect was significantly more pronounced in the non-staple group. Similarly, hypolordosing effect was slightly more pronounced in the non-staple group although it did not reach statistical significance. Details are given in table 2.

In the first erect radiographs mean UIV screw - UIV upper end-plate Cobb angle was 4.30 \pm 2.80 for staple and $6.90 \pm 3.90$ for non-staple groups, showing no difference $(U=43, p=0.060)$. However, the change in this angle between first erect 
Table 2: Radiographic measurements of coronal and sagittal parameters

\begin{tabular}{|c|c|c|c|c|c|}
\hline & \multicolumn{2}{|c|}{ Staple } & \multicolumn{2}{|c|}{ Non-Staple } & \multirow[b]{2}{*}{ Statistics } \\
\hline & Mean \pm SD & Min-Max & Mean \pm SD & Min-Max & \\
\hline \multicolumn{6}{|l|}{$\begin{array}{c}\text { Main Thoracic } \\
\text { Curve }\end{array}$} \\
\hline Preoperative & $47.4 \pm 8.9$ & $38-68$ & $46.5 \pm 7.0$ & $36-59$ & $U=89, p=0.942$ \\
\hline Correction \% & $50.2 \pm 14.6$ & $40-72$ & $53.9 \pm 9.6$ & $39-67$ & $U=79, p=0.560$ \\
\hline $\begin{array}{l}\text { Change in } 12 \\
\text { weeks }\end{array}$ & $-1.6 \pm 2.4$ & $-6-2$ & $-1.5 \pm 6.2$ & $-15-9$ & $U=90, p=0.984$ \\
\hline \multicolumn{6}{|l|}{ Lumbar Curve } \\
\hline Preoperative & $29.4 \pm 8.5$ & $14-42$ & $29.8 \pm 5.2$ & $22-35$ & $U=91, p=1.000$ \\
\hline Correction \% & $47.0 \pm 25.0$ & $14-93$ & $39.8 \pm 22.2$ & $13-81$ & $U=62, p=0.384$ \\
\hline $\begin{array}{l}\text { Change in } 12 \\
\text { weeks }\end{array}$ & $-1.8 \pm 5.6$ & $-15-6$ & $-1.3 \pm 3.9$ & $-6-5$ & $U=76, p=0.936$ \\
\hline \multicolumn{6}{|l|}{ Kyphosis } \\
\hline Preoperative & $29.8 \pm 8.3$ & $15-44$ & $32.6 \pm 12.5$ & $17-59$ & $U=80, p=0610$ \\
\hline $\begin{array}{l}\text { Change after } \\
\text { surgery }\end{array}$ & $-0.3 \pm 5.2$ & $-7-11$ & $-6.6 \pm 6.9$ & $-15-11$ & $U=33, p=0.004$ \\
\hline $\begin{array}{l}\text { Change in } 12 \\
\text { weeks }\end{array}$ & $0.1 \pm 5.4$ & $-8-13$ & $0.2 \pm 6.6$ & $-13-9$ & $U=83, p=0.697$ \\
\hline \multicolumn{6}{|l|}{ Lordosis } \\
\hline Preoperative & $58.9 \pm 15.5$ & $37-72$ & $62.4 \pm 7.8$ & $49-71$ & $U=80, p=0.610$ \\
\hline $\begin{array}{l}\text { Change after } \\
\text { surgery }\end{array}$ & $-5.5 \pm 5.4$ & $-13-4$ & $-10.9 \pm 6.7$ & $-21-2$ & $U=55, p=0.084$ \\
\hline $\begin{array}{l}\text { Change in } 12 \\
\text { weeks }\end{array}$ & $2.0 \pm 4.4$ & $-6-10$ & $5.8 \pm 7.4$ & $-7-19$ & $U=59, p=0.119$ \\
\hline
\end{tabular}

SD: standard deviation, Min: minimum, Max: Maximum

and 6 to 12-weeks postoperative radiographs was significantly higher $(U=34, p=0.016)$ in nonstaple group, with mean values of $1.40 \pm 2.30$ (range $-10-60$ ) and $5.1 \pm 4.6$ (range 0o-14.20) in staple and non-staple groups, respectively. Two out of the $14(14.3 \%)$ patients had a change $>50$ in the UIV screw - UIV upper end-plate angle in the staple group, compared to 6 out of $13(46.2 \%)$ in the non-staple group. Angular changes between screws were not different between groups $(U=55, p=0.225)$ with mean values of $0.80 \pm 0.30$ (range $00-10$ ) and $1.10 \pm 0.60$ (range $0.50-2.80$ ) in staple and non-staple groups, respectively.

\section{Return to Activities of Daily Living}

The mean hospitalization period was $3.9 \pm 0.6$ (range 3-5) days for staple and 3.5 \pm 0.7 (range 3-5) for non-staple groups, showing no differen- ce $(U=55, p=0.085)$. The mean days to return to school was $9.5 \pm 2.7$ (range 6-14) days for staple and 9.2 \pm 2.4 (range 6-14) for non-staple groups, showing no difference $(U=85, p=0.787)$. All patients in both surgical groups reached rehabilitation goals described in table 1.

\section{Surgical Outcomes}

The mean preoperative height was $157.2 \pm 9.9$ (range 139-183) cm for staple and $153.7 \pm 10.7$ (range 130-172) cm for non-staple groups, showing no difference $(U=78, p=0.607)$. Similarly, postoperative mean heights were not different $(U=72, p=0.299)$ between groups with a mean increase of $1.9 \pm 0.9$ (range 1-4) and $2.4 \pm 1.7$ (range 1-6) for staple and non-staple groups, respectively. In contrast, last follow-up heights were significantly different $(U=14.5, p=0.035)$ 
between groups with a mean increase of $3.7 \pm 2.0$ (range 1-6) and 7.8 \pm 4.4 (range 3-17) for staple and non-staple groups, respectively. As followup pulmonary function tests are performed in the 12th month control, patients in the staple did not yet have postoperative forced vital capacity measurements when this manuscript was written. In the non-staple group, the mean forced vital capacity improvement was $574 \pm 352 \mathrm{ml}$ (range 180-1220).

\section{Patient-Reported Outcomes}

Preoperatively mean SRS-22 function score was 4.60 (range 4.4-5) and 4.35 (range 2-5) which improved to 4.70 (range 4-5) and 4.72 (range 3.40-5) postoperatively for staple and nonstaple groups, respectively. Preoperatively mean SRS-22 pain score was 4.42 (range 3.2-5) and 4.44 (range 2.6-5) which improved to 4.73 (range 4.2-5) and 4.80 (range 4.4-5) postoperatively for staple and non-staple groups, respectively. Preoperatively mean SRS-22 self-image score was 3.33 (range 2.2-4.6) and 3.35 (range 2.4-4.8) which improved to 4.27 (range $3.2-5$ ) and 4.43 (range 3.2-5) postoperatively for staple and non-staple groups, respectively. Preoperatively mean SRS-22 mental-health score was 3.74 (range $3.2-5$ ) and 3.60 (range 3-4.2) which improved to 3.82 (range 3-4.2) and 3.97 (range 3.2-4.2) postoperatively for staple and nonstaple groups, respectively.

Overall, pre- and post-operative SRS22 subtotal scores were not different $(U=65$, $p=0.794$ and $U=44, p=0.497$ ) between groups with a mean score of 4.05 (range 3.3-4.47) and 3.93 (range 2.5-4.75) which improved to 4.37 (range 3.75-4.75) and 4.48 (range 3.7-4.8) postoperatively for staple and non-staple groups, respectively. Patient reported mean satisfactions were 4.78 (range 3.5-5) and 4.75 (range 4-5) for staple and non-staple groups, respectively, that showed no difference $(U=45.5, p=0.568)$

\section{Complications}

One patient in the staple group had pleural effusion after thoracic tube removal that required reinsertion of a thoracic tube.

Two patients in the non-staple group had atelectasis that was resolved with pulmonary physical therapy. One patient had a loosening at the LIV screw in one-year control radiographs. There are 2 overcorrection candidates with minimum curvature and remaining growth potential.

None of the screw angles, in both groups, changed $₫ 60$, which suggests that none of the tethers were broken.

\section{Discussion}

This report demonstrates good and rapid functional outcomes and high patient satisfaction rate with improvement in function, pain, self-image and mental health in patient-reported outcomes. This report further demonstrates the efficacy of the use of staples during anterior vertebral body tethering for skeletally immature patients. Although correction rates were similar in the staple and non-staple groups, the results of this study suggest that the use of staples may help decrease implant-related complication.

To date, spinal fusion remains the most viable surgical option in surgical treatment for AIS. Yet, fusion comes with decreased spinal range of motion and mobility, inhibition of growth in the operated levels and possible development of adjacent segment degeneration (Danielsson, Romberg, \& Nachemson, 2006; Green et al., 2011; Kepler, Meredith, Green et al., 2012).

Growth- and motion-sparing strategies that modulate the growth of the spine while stabilizing/correcting the curve are alternatives to fusion for the treatment of progressive AIS. Growth modulation with VBT depends on the remaining growth of the child. The rationale behind applying compression to the convexity of the curve is based on the Hueter-Volkmann law. This law states that a growth plate under pressure will grow more slowly than one that is subjected to less pressure (Mehlman, Araghi, \& Roy, 1997).

In this consecutive patient series, mean hospitalization period and return to school after VBT surgery suggests a rapid recovery period after this minimally invasive surgical approach. As VBT is a non-fusion growth-modulation technique, the patients grow taller as the follow-up period increases. Improvement in their forced vital capacity also suggests that the growth of the spine is accompanied by the growth of the thoracic cage. 
Overall, reports on VBT look promising with additional time and growth-dependent correction attained after initial surgery (Samdani et al., 2014, 2015). With this powerful technique, there is even a possibility for overcorrection and reversing of the curve. Previous reports display 52$54 \%$ initial correction in the main thoracic curve accompanied by $28-41 \%$ correction in the compensatory lumbar curve (Samdani et al., 2014, 2015). The results of this study are comparable to those previously reported.

Samdani et. al.(Samdani et al., 2015) reported a slight decrease in mean early postoperative thoracic kyphosis that reached back to initial values during follow-up. In this study, the hypokyphosing effect of the surgery was more pronounced in non-stable group. Kyphosis restoration is one of the goals of the surgery for AIS. Although coronal correction was similar, on average, staple group displayed 40 more kyphosis restoration. This may be due to better positioning of the screw in the antero-posteior aspect of the body when using staples.

The results of this study further suggest a hypolordosing effect, which is slightly more pronounced in non-stable group with an average of 50 less lordosis although it did not reach significance. This effect is likely due to coupled motion and compensation for the hypokyphosis.

Persistent atelectasis, worsening of the deformity and overcorrection are reported as the complications of VBT surgery (Samdani et al., 2014, 2015). No neurologic, infectious, or implant-related complications were reported. Anecdotal instances of tether breakage raised concerns about implant related complications in VBT. As tether breakage, other implant related complications may require close observation to identify.

Ten months, being the minimum follow-up period for non-staple group and the maximum follow-up for staple group, reflects the transition to using staples during the experience with this surgical technique.

Intra-operatively, all screws were placed parallel to the upper end-plate. The tether was then placed within the tulips of the screws. Set screws on each screw were tightened one by one while achieving correction through both tensi- oning of the tether and translation of the spine. The screws may migrate within the vertebral body during these maneuvers, usually at the UIV.

Preoperative mean main thoracic curve magnitude and mean operative main thoracic curve correction was similar in two groups suggesting similar application of corrective strategies and maneuvers. Mean UIV screw - UIV upper endplate Cobb angle was 2.60 higher in the nonstaple group although this did not reach statistical significance. This might be due to augmented resistance by the staple given that they were subjected to similar forces. Likewise, during the relaxation/adaptation period, the UIV screws revealed more alteration in their direction. Average change in the non-staple group was 5.10, and almost half of the patients had a change $>50$ (Figure 1). This suggests that the increased curve magnitude during this period might result in more tensioning on the tether that alters the position of the screw within the vertebral body before screw-bone interface fusion occurs. One patient in the non-staple group further developed LIV screw loosening that became evident in the postoperative one-years' radiograph. In contrast, UIV screws remained more stable during the relaxation period displaying 1.40 of average change in position which is within the range of measurement error (Figure 2). This suggests that the 4-prong staple might assist overcoming mechanical loads generated during relaxation period.

This suggested difference in resistance to biomechanical loads in this study might be important in planning postoperative rehabilitation. Passive and active positioning to loosen the already over-tensioned tether might decrease the loads generated at the UIV screw. Activities of daily living might also require modification. Yet, in this study, the rehabilitation protocol and the exercises were the same for both groups. All patients in both groups reached their rehabilitation goals and reported similar health-related quality-oflife scores.

The main limitation of this study is its retrospective nature. Transition to using staples were chosen arbitrarily. Since the same rehabilitation protocol is used in both groups, the possible effect of modified rehabilitation protocols in dec- 


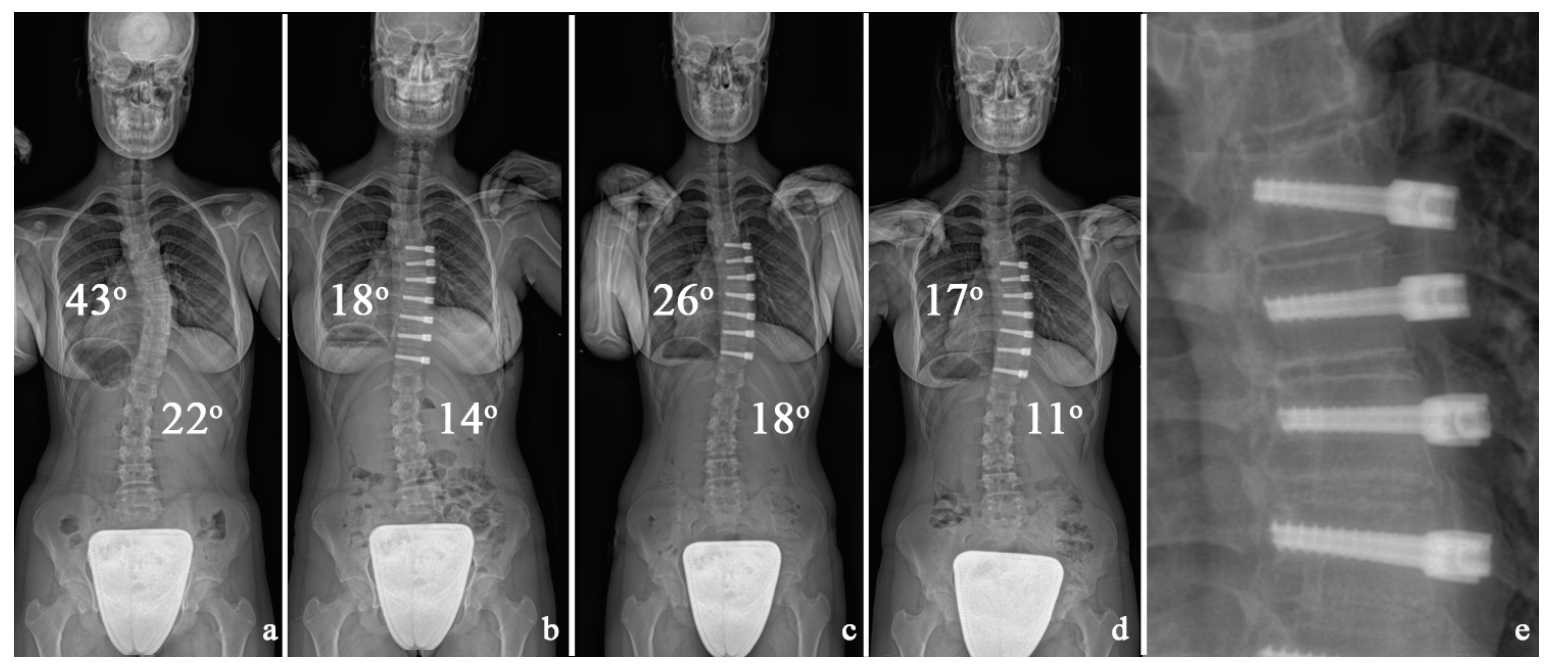

Figure 1: (a) Preoperative, (b) postoperative first-erect, (c) 3-months, and (b) 1-year AP radiographs of a 13-year-old girl. She underwent vertebral body tethering of T5 to T11 without using staples. UIV screw - UIV upper end-plate Cobb angle was 11.70 in the first erect radiograph, which increased to 20.70 during the relaxation period. (e) At 1 -year, this angle was 19.30.
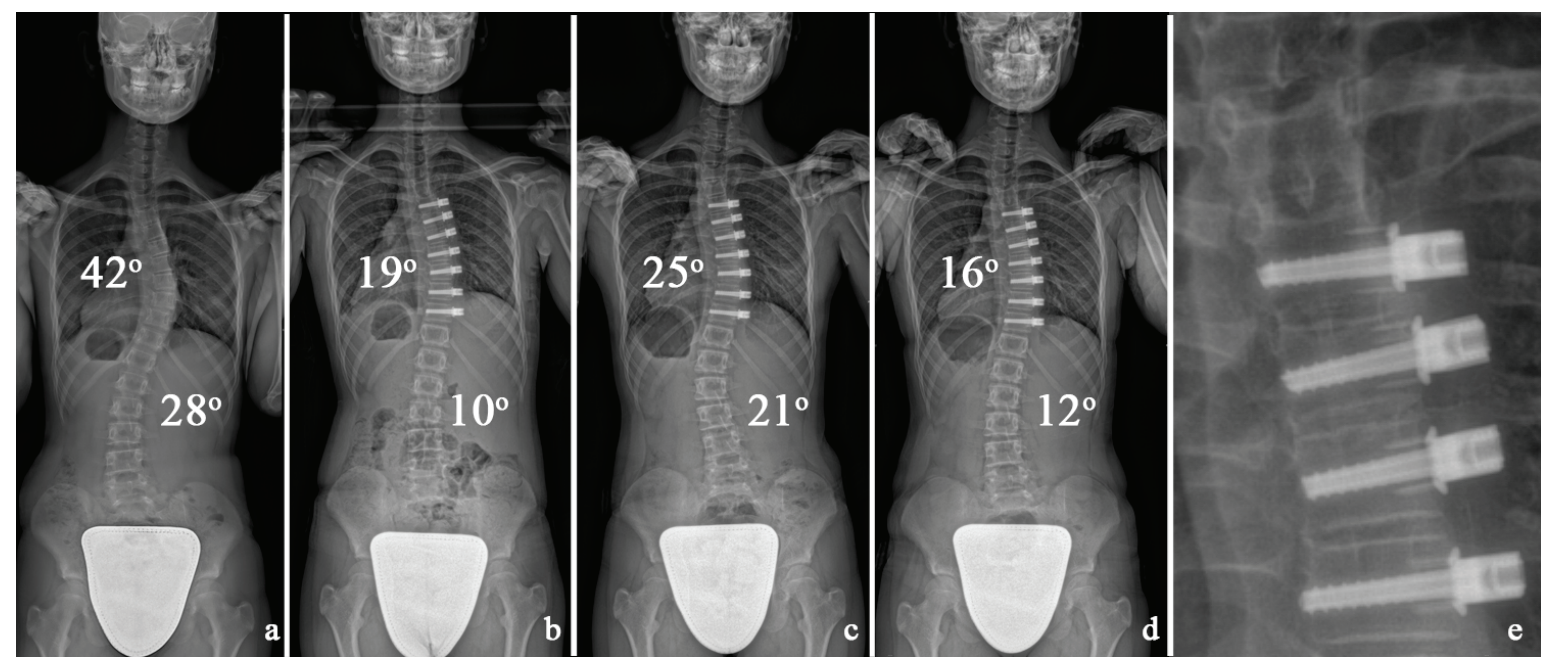

Figure 2: (a) Preoperative, (b) postoperative first-erect, (c) 3-months, and (b) 1-year AP radiographs of a 13-year-old girl. She underwent vertebral body tethering o f T5 to T11 using staples to facilitate screw insertion. UIV screw - UIV upper end-plate Cobb angle was 4.70 in the first erect radiograph, which increased to 4.40 during the relaxation period. (e) At 1-year, this angle was 4.20.

reasing implant-related complication rates when staples are not used cannot be determined. This warrants future research.

\section{Conclusions}

The use of staples to assist screw insertion in anterior vertebral body tethering appears to be safe and efficient. Furthermore, the use of staples may lower UIV screw migration and other imp- lant-related complications. VBT surgery revealed good functional and surgical outcomes, and high patient satisfaction rate with improvement in function, pain, self-image and mental health in patient-reported outcomes regardless of the use staples.

\section{Aknowlegments}

The author thanks Dr. Yasemin Yavuz of the De- 
partment of Biostatistics, Ankara University, Dr. Ahmet Alanay of the Department of Orthopedics and Traumatology, Acibadem Mehmet Ali AydinIar University School of Medicine and Fzt. Funda işler of the Acibadem Maslak Hospital.

\section{References}

Akbarnia BA. (2007). Management themes in early onset scoliosis. J Bone Joint Surg Am; 89(suppl 1):42-54.

Asher MA, Burton DC. (2006). Adolescent idiopathic scoliosis: natural history and long term treatment effects. Scoliosis; $31 ; 1(1): 2$.

Braun, J. T., Akyuz, E., Ogilvie, J. W., \& Bachus, K. N. (2005). The efficacy and integrity of shape memory alloy staples and bone anchors with ligament tethers in the fusionless treatment of experimental scoliosis. J Bone Joint Surg Am, 87(9), 2038-2051.

Cebeci, B. O., Ergene, G., Sogunmez, N., Ay, B., Yilgor, C., \& Alanay, A. (2017). Non-Fusion Growth Modulation with Anterior Vertebral Body Tethering via Thoracoscopic Approach for Adolescent Idiopathic Scoliosis. Spine J, 17(10), s106.

Charles, Y. P., Daures, J. P., de Rosa, V., \& Dimeglio, A. (2006). Progression risk of idiopathic juvenile scoliosis during pubertal growth. Spine (Phila Pa 1976), 31(17), 1933-1942.

Danielsson, A. J., Romberg, K., \& Nachemson, A. L. (2006). Spinal range of motion, muscle endurance, and back pain and function at least 20 years after fusion or brace treatment for adolescent idiopathic scoliosis: a case-control study. Spine (Phila Pa 1976), 31(3), 275-283.

Gomez, J. A., Hresko, M. T., \& Glotzbecker, M. P. (2016). Nonsurgical Management of Adolescent Idiopathic Scoliosis. J Am Acad Orthop Surg, 24(8), 555-564.

Green, D. W., Lawhorne, T. W., 3rd, Widmann, R. F., Kepler, C. K., Ahern, C., Mintz, D. N., et al. (2011). Long-term magnetic resonance imaging follow-up demonstrates minimal transitional level lumbar disc degeneration after posterior spine fusion for adolescent idiopathic scoliosis. Spine (Phila Pa 1976), 36(23), 1948-1954.

Guille, J. T., D'Andrea, L. P., \& Betz, R. R. (2007). Fusionless treatment of scoliosis. Orthop Clin North Am, 38(4), 541-545, vii.

Kepler, C. K., Meredith, D. S., Green, D. W., \& Widmann, R. F. (2012). Long-term outcomes after posterior spine fusion for adolescent idiopathic scoliosis. Curr Opin Pediatr, 24(1), 68-75.

MehIman, C. T., Araghi, A., \& Roy, D. R. (1997). Hyphenated history: the Hueter-Volkmann law. Am J Orthop (Belle Mead NJ), 26(11), 798-800.
Newton, P. O., Upasani, V. V., Farnsworth, C. L., Oka, R., Chambers, R. C., Dwek, J., et al. (2008). Spinal growth modulation with use of a tether in an immature porcine model. J Bone Joint Surg Am, 90(12), 26952706.

Samdani, A. F., Ames, R. J., Kimball, J. S., Pahys, J. M., Grewal, H., Pelletier, G. J., et al. (2014). Anterior vertebral body tethering for idiopathic scoliosis: twoyear results. Spine (Phila Pa 1976), 39(20), 16881693.

Samdani, A. F., Ames, R. J., Kimball, J. S., Pahys, J. M., Grewal, H., Pelletier, G. J., et al. (2015). Anterior vertebral body tethering for immature adolescent idiopathic scoliosis: one-year results on the first 32 patients. Eur Spine J, 24(7), 1533-1539.

Weinstein, S. L., Dolan, L. A., Wright, J. G., \& Dobbs, M. B. (2013). Effects of bracing in adolescents with idiopathic scoliosis. N Engl J Med, 369(16), 15121521.

Yilgor, C., \& Alanay, A. (2017). Novel Non-Fusion GrowthModulation Techniques for Pediatric Scoliosis. In S. Berven \& M. de Kleuver (Eds.), AOSpine Master Series, Vol 9. Pediatric Spinal Deformity. (pp. 53-62): Thieme. 